\title{
Hypoglossal Nerve
}

National Cancer Institute

\section{Source}

National Cancer Institute. Hypoglossal Nerve. NCI Thesaurus. Code C12732.

The twelfth cranial nerve. It arises from the hypoglossal nucleus and leads to the tongue. 